\title{
Do Children and Adolescents Prefer Pediatric Attire over White Attire during Dental Appointments? A Meta-analysis of Prevalence Data
}

\author{
Deise RA Kastelic ${ }^{1}$, Luiz ER Volpato ${ }^{2}$, Ana TS de Campos Neves ${ }^{3}$, Andreza M Aranha ${ }^{4}$, Carolina Castro Martins ${ }^{5}$
}

\begin{abstract}
Purpose: To evaluate the preferences of children and adolescents regarding the professional attire used by dentists (pediatric or white attire). Materials and methods: Seven electronic databases were searched without restriction regarding language and publication date. The primary outcome was the preference of patients regarding pediatric or white attire; secondary outcomes were preference for a female or male dentist and the use of personal protective equipment or not. We ran a meta-analysis of prevalence data of preferences, calculating effect estimate (ES), $95 \% \mathrm{Cl}$, subgrouped by anxiety status and sex of the patient. Z-test of interactions was used to compare prevalence between groups ( $p<0.05)$. Results: Fourteen cross-sectional studies were included, consisting of 5,756 patients with ages ranging from 2 to 15 years. Anxious children preferred more pediatric attire (ES: $0.03 ; 95 \% \mathrm{Cl}: 0.02,0.03)$ than non-anxious children (ES: $0.02 ; 95 \% \mathrm{Cl}: 0.01,0.02)(p=0.0085)$. Female dentists were preferred (ES: $0.62 ; 95 \% \mathrm{Cl}: 0.52,0.72)$ over male dentists (ES: $0.40 ; 95 \% \mathrm{Cl}: 0.30,0.49)(p=0.003)$ in general and by the girls (ES: $0.41 ; 95 \%$ $\mathrm{Cl}: 0.25,0.56)$ but not by boys (ES: $0.20 ; 95 \% \mathrm{Cl}: 0.09,0.30)(p=0.036)$.

Conclusion: There is no difference in the preferences of children and adolescents regarding a specific attire. Anxious children and adolescents preferred dentists using pediatric attire. In general, female dentists were preferred over male dentists and also were preference among girls.

Keywords: Adolescent, Child, Dentists, Patient preference.

International Journal of Clinical Pediatric Dentistry (2021): 10.5005/jp-journals-10005-1861
\end{abstract}

\section{INTRODUCTION}

A friendly relationship and good communication between the child and dentist are important for the success of dental treatment, improving the quality of dental care. ${ }^{1}$

During the first visit to the dentist, even before verbal communication, children develop an impression of the dentist based on his/her appearance, movements, and gestures. ${ }^{1-3}$ In this context, the appearance and the professional attire used are considered important as they influence the development of the professional-patient relationship ${ }^{4}$ and can contribute to the establishment of empathy in the dental consultation.,

Professional attire has changed over time. The conventional white attire has been a symbol for the medical profession for more than a century since it represents purity and cleanliness. ${ }^{7}$ More recently, professional clothing has been influenced by a less formal fashion look. ${ }^{8}$ Examples of dressing such as "clown doctors" and friendly or pediatric attires have been increasingly used for the management of anxiety in pediatric dentistry. ${ }^{6,9}$ However, the actual preference of the patients for these attires is still lacking in evidence to encourage its use to make patients feel more comfortable in the dental environment and improve the quality of the consultations. . $^{3,10,11}$

This study aimed to systematically review the scientific evidence regarding the preferences of children and adolescents on dentists' professional attire.

\section{Materials and Methods}

\section{Protocol}

The present systematic review was undertaken in accordance with the guidelines of the Preferred Reporting Items for Systematic
${ }^{1-4}$ Cuiabá Dental School, Universidade de Cuiabá, Cuiabá, MT, Brazil

${ }^{5}$ Department of Pediatric Dentistry, Universidade Federal de Minas Gerais, Belo Horizonte, MG, Brazil

Corresponding Author: Luiz ER Volpato, Cuiabá Dental School, Universidade de Cuiabá, Cuiabá, MT, Brazil, Phone: +91 556536221538 , e-mail: odontologiavolpato@uol.com.br

How to cite this article: Kastelic DRA, Volpato LER, de Campos Neves ATS, et al. Do Children and Adolescents Prefer Pediatric Attire over White Attire during Dental Appointments? A Meta-analysis of Prevalence Data. Int J Clin Pediatr Dent 2021;14(1):14-29

Source of support: Nil

Conflict of interest: None

Reviews and Meta-Analyses (PRISMA). ${ }^{12}$ The protocol for this systematic review was registered on PROSPERO \#CRD42018102177.

\section{Clinical Question}

The PECO question was: What are the preferences of children and adolescents regarding dentists' professional attires? Patients: children and adolescents; Exposure: pediatric or colorful attires; Comparison: white attires; Outcome: preference.

\section{Search Strategy}

In selecting terms for the search strategy, descriptors of the Medical Subject Headings (MeSH) related to the clinical question were used.

Seven electronic databases were searched until February 2017. There was no restriction of date of publication or language. Search strategies for each database are depicted in Table 1. 
Table 1:The electronic database searched and respective search strategy

\begin{tabular}{ll}
\hline Database & Search strategy \\
\hline Medline through PubMed, & (white coats OR white-coat OR lab coat \\
Scopus, Cochrane, Web of & OR attire OR medical coat OR medical \\
Science & coats OR dental coat OR dental coats \\
& OR professional appearance OR profes- \\
& sional appearances OR clothing) AND \\
& (fear OR stress OR behavior OR behav- \\
& iors OR attitude OR perceptions) AND \\
& (dental OR dental care OR dentistry OR \\
& oral care OR oral health) \\
& ("white coats" OR "white-coat" OR "lab \\
& coat" OR attire OR "medical coat" OR \\
& "medical coats" OR "dental coat" OR \\
& "dental coats" OR "professional appear- \\
& ance" OR "professional appearances") \\
Proquest & AND (fear OR stress OR behavior OR \\
& behaviors OR attitude OR perceptions) \\
& AND (dental OR dentistry OR "oral care" \\
& OR "oral health") \\
& (white coats OR white-coat OR lab \\
& coat OR attire OR medical coat OR \\
& medical coats OR dental coat OR \\
& dental coats OR professional appear- \\
ance OR professional appearances OR \\
clothing[search tool]) AND (fear[search \\
tool] OR stress OR behavior OR \\
behaviors OR attitude[search tool] \\
OR perceptions[search tool]) AND \\
(dental OR dental care[search tool] OR \\
dentistry[search tool] OR oral care OR \\
oral health[search tool]). \\
Attire \\
White coat \\
Lab coat \\
\hline
\end{tabular}

\section{Inclusion and Exclusion Criteria}

The inclusion criteria were observational studies that evaluated professional attire that compared two or more types of attires; directed to dentistry or dentist; involved perception/preference of children and/or adolescents.

Exclusion criteria were: literature reviews, systematic reviews, case reports, editorials, studies that did not report professional attire; studies on hypertension in medicine or nursing; biosafety or protection; studies regarding medical and/or nursing professionals.

\section{Study Selection and Data Extraction}

The study selection process was performed by two independent reviewers. First, the reviewers independently selected all studies retrieved from the electronic databases, based on the inclusion criteria applied to the titles and abstracts. For studies meeting the inclusion criteria or for those with insufficient data in the title and abstract, the full text was selected for a full reading. The independent reviewers were calibrated in accordance with the inclusion/exclusion criteria using a sample of $10 \%$ of the retrieved studies and the agreement between reviewers was found to be good $(K=0.846)$. After the selection of titles and abstracts, independent reviewers selected studies based on the full texts.

Two independent reviewers extracted data and used a standardized form. We extracted data regarding the author's name; year of publication; geographical location; study design; characteristics of participants, sample, exposure [professional attire, use of personal protective equipment (PPE), sex of the dentist], age, and sex of children and adolescents, anxiety status.

In case of missing or misunderstood data, the authors were personally contacted by e-mail.

\section{Risk of Bias}

We used the Newcastle-Ottawa Quality Assessment Scale for casecontrol studies modified for use on the cross-sectional studies. ${ }^{13,14}$ The risk of bias was evaluated regarding the included studies' selection (representativeness of the sample, sample size, nonrespondents, and ascertainment of exposure), comparability (based on design and analysis), and outcome (assessment of the outcome and statistical test). Disagreements were resolved by a consensus. The final score could vary from 0 to a maximum of 8 points.

\section{Meta-analysis}

We used STATA software (StataCorp. 2009. Stata Statistical Software: version 11, College Station, TX, USA) for meta-analysis. The primary outcome was the preference for the dentist attire: pediatric attire and white attire. Secondary outcomes were preference for the sex of the dentist and preference for the use of PPE. We extracted absolute numbers related to preferences and sample size. Data were extracted according to the reported papers and only those papers in which data could be extracted were included in the meta-analysis.

Statistical heterogeneity was calculated by $R^{2}$ statistics. ${ }^{15}$ The Mandel-Haenszel random effect model was used when there was a statistically significant heterogeneity $(p<0.05)^{15}$ and for the subgroup analysis. We subgrouped for boys and girls regarding preferences of pediatric/white attire and female/male dentists. For those variables that had enough data to be abstracted, a subgroup analysis was run for anxiety (anxious/non-anxious children) and sex (girls/boys) pediatric. The overall effect estimate (ES) of prevalence was calculated for pediatric attire, white attire, male dentist and female dentist, PPE or no PPE. The respective $95 \% \mathrm{CI}$ was calculated. The statistical difference between the ES of boys/girls, anxious/not anxious, pediatric/white attire, male/female dentist, PPE/no PPE was calculated using a $Z$-test and respective $p$ values. ${ }^{16}$ Statistical significance was considered at $p \leq 0.05$.

No funnel plot was performed for publication bias as there were not enough studies to be included in the meta-analysis. ${ }^{17}$

\section{Results}

\section{Summary of Article Selection and Data Extraction}

After removing duplicates $(n=121)$, the electronic search yielded 1,615 potentially relevant references. Initially, 1,592 publications were excluded following the evaluation of the titles and abstracts. The full texts of the remaining 23 articles were read and 9 articles were excluded in this second phase. Thus, a total of 14 crosssectional studies were included. Flowchart 1 illustrates the selection using the PRISMA flow diagram. ${ }^{12}$

\section{Description of the Included Studies}

The included studies were comprised of 5,756 children and adolescents, with ages ranging from 2 to 15 years. Studies were from India $(n=6)$, Turkey $(n=2)$, Saudi Arabia $(n=2)$, the United States $(n=2)$, Singapore $(n=1)$, and England $(n=1)$.

All 14 included studies assessed the preferences of children and adolescents for the type of attire used by the dentist. In all of them, each child or adolescent was asked to choose pictures that indicated 
Flowchart 1: PRISMA flow diagram summarizing article selection

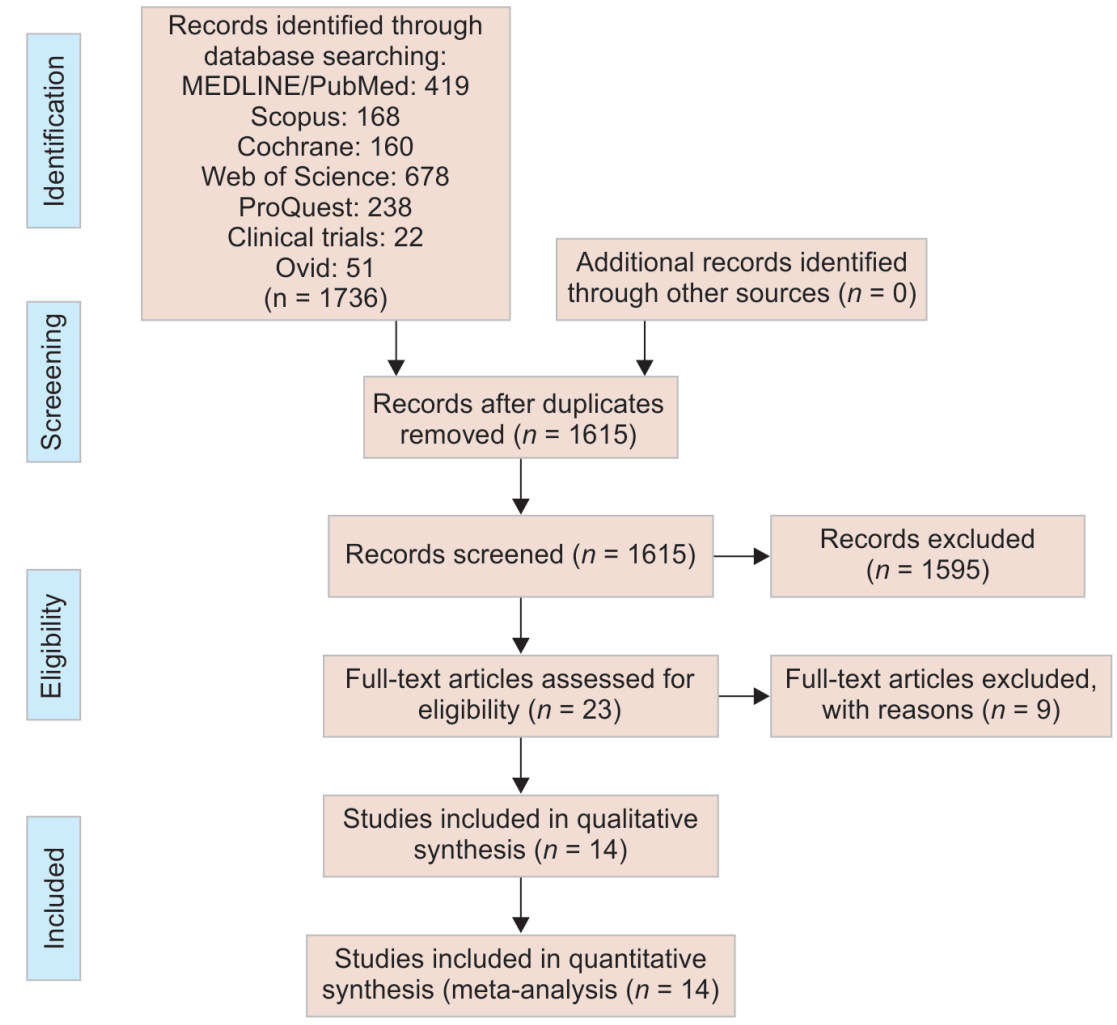

their preference regarding the type of attire used by the dentist. Four studies had questionnaires that were answered by the children and adolescents' parents. ${ }^{4,11,18,19}$ In addition to the attire, 9 studies evaluated the preference of children and adolescents in relation to the use of PPE by dentists $1,3,4,10,11,18,20-22$ and 10 evaluated the sex of the dentist. ${ }^{1,3,4,10,11,18-20,22,23}$ Six studies evaluated the opinions of anxious and non-anxious children and adolescents. ${ }^{1,6,19-21,24}$ The other characteristics of the studies are presented in Table 2.

\section{Risk of Bias}

The scores of Newcastle-Ottawa modified scale varied from $8,^{19}$ $7,{ }^{20,24} 6,^{6,10} 5,{ }^{3,4,21} 4,^{1,11,18,22,25}$ and $3^{23}$ (Table 3).

\section{Meta-analysis}

Fourteen studies were included in the meta-analy sis. ${ }^{1,3,4,6,10,11,18-20,22-25}$ Table 4 shows the prevalence (ESs) and 95\% $\mathrm{Cl}$ of preferences among children and adolescents. Supplementary Figs 1 to 12 show the corresponding forest plots. In general, the overall prevalence of preference for pediatric attire was 0.33 (95\% $\mathrm{Cl}: 0.20,0.47)$ and $0.41(95 \% \mathrm{Cl}: 0.20,0.61)$ for white attire $(p=0.325)$. We subgrouped by anxiety and sex without a difference in the preference of use of pediatric or white attire. However, subgroup analysis for anxiety showed that anxious children/adolescents preferred pediatric attire (ES: $0.03 ; 95 \% \mathrm{Cl}: 0.02,0.03$ ) compared to non-anxious children/adolescents (ES: $0.02 ; 95 \% \mathrm{Cl}: 0.01,0.02$ ) $(p=0.0085)$.

In general, a female dentist (ES: $0.62 ; 95 \% \mathrm{Cl}: 0.52,0.72)$ was preferred over a male dentist (ES: $0.40 ; 95 \% \mathrm{Cl}: 0.30,0.49)(p=$ $0.003)$, and girls preferred a female dentist (ES: $0.41 ; 95 \% \mathrm{Cl}: 0.25$, $0.56)$ compared to boys (ES: $0.20 ; 95 \% \mathrm{Cl}: 0.09,0.30)(p=0.036)$. Preferences for a male dentist by sex and preferences for the use of PPE not did not differ.

\section{Discussion}

There is a changing trend concerning the attire used for pediatric care in dental care environments. However, no systematic review or meta-analysis was found addressing whether or not there is scientific evidence supporting this change.

The overall results showed that there is no difference between the preference for white or pediatric attire among children and adolescents, even when they were subgrouped by sex. However, the preference for pediatric attire was higher among anxious children and adolescents than among the non-anxious ones. Children and adolescents had a higher preference for female dentists than for male dentists. Girls preferred female dentists more than boys. Also, the use of PPE was not a concern among children and adolescents.

Recent studies have shown the preference of children and adolescents for the use of white attires by dentists, ${ }^{3,4,10,11,18,24}$ while others encourage the use of "child friendly attire". 6,20 This may confound the dentist while choosing his or her professional attire. The preference for the professional wearing white attire ${ }^{1,3,4,6,10,18,24}$ suggests an image of professionalism that would increase confidence. ${ }^{1,18,26}$ Contrary to the popular belief that children are afraid of professionals wearing white attires, more formal dressing would portray a more competent and committed professional. ${ }^{27}$ The white attire also seems to be seen as a symbol of "healing"10. Despite recent changes in Western culture in favor of more casual dressing styles, there seems to still be a preference for the dentist's formal attire. ${ }^{3,11}$ Also, children may have become used to the conventional attire that health professionals wear by visiting the pediatrician and family doctors from an early age depending on the socioeconomic status of the country they reside in. They may have also become acquainted with health professionals seen in the 


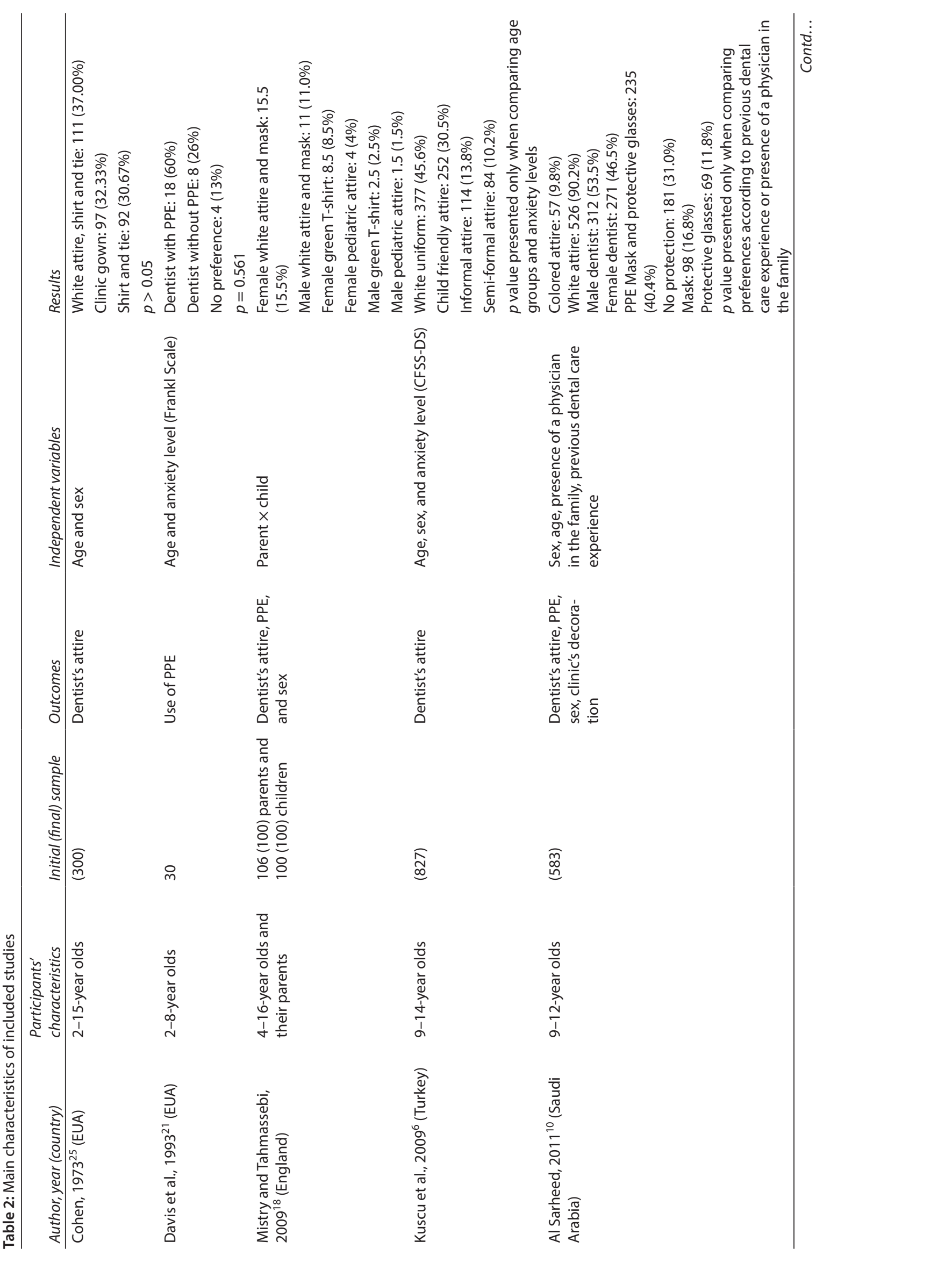




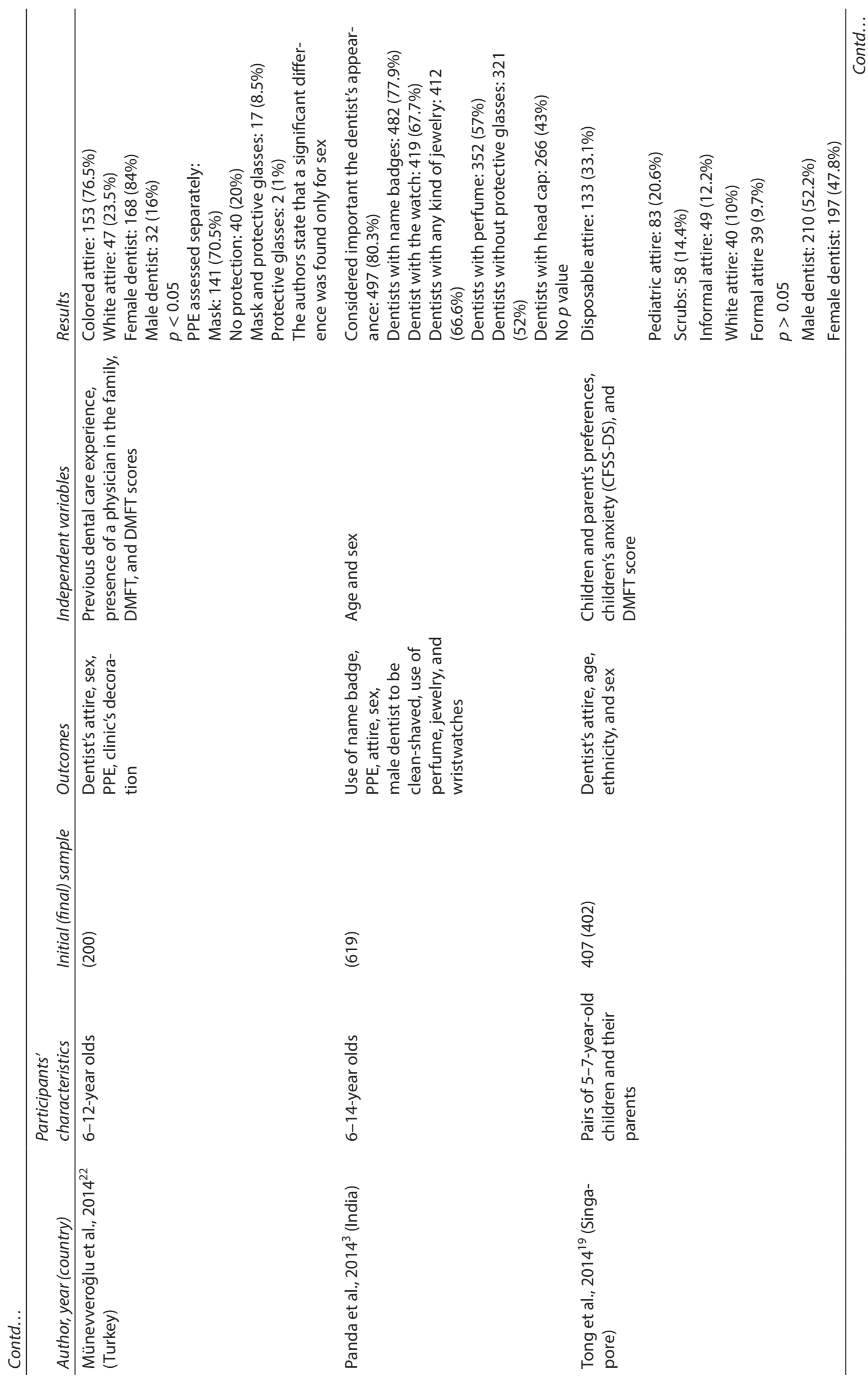




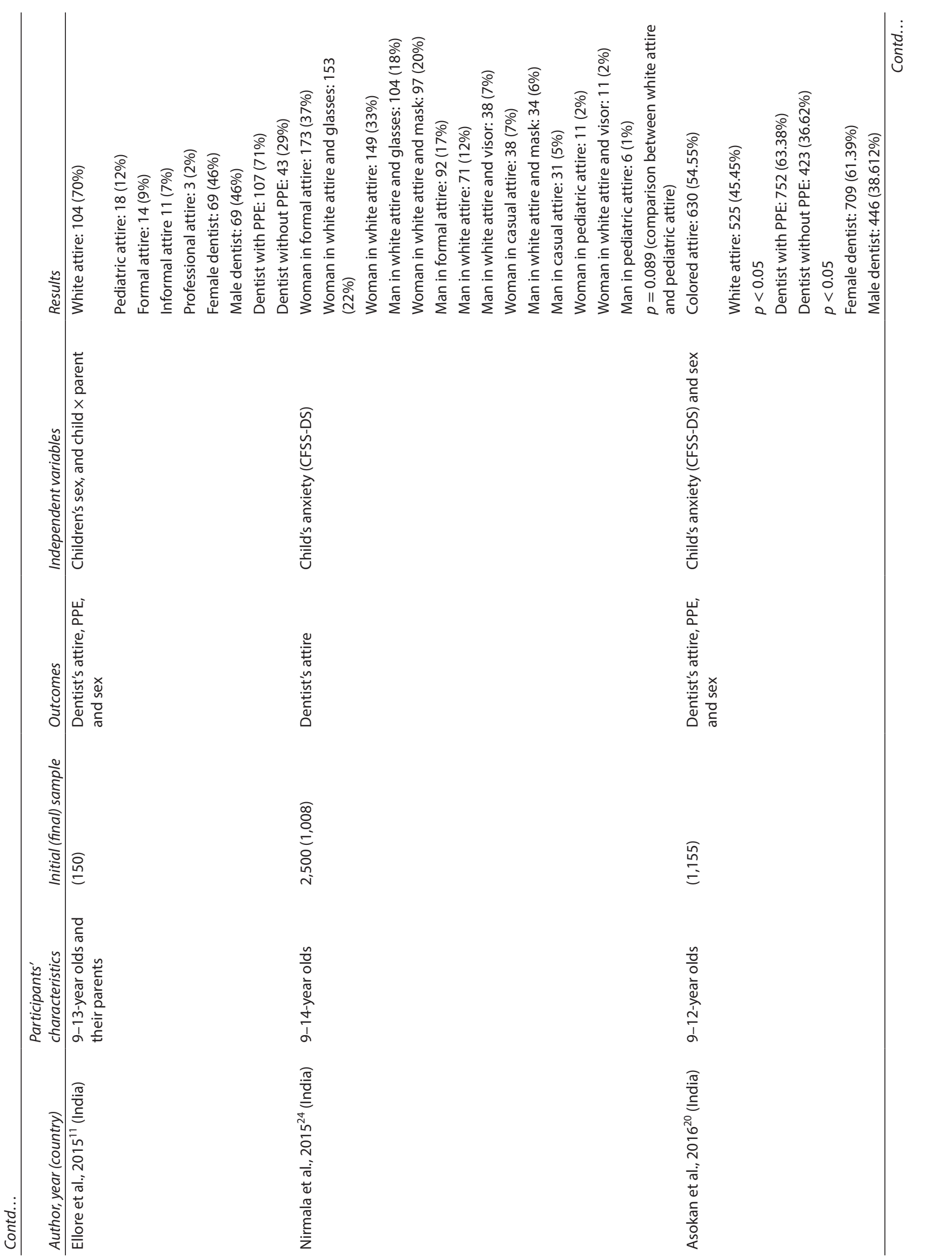




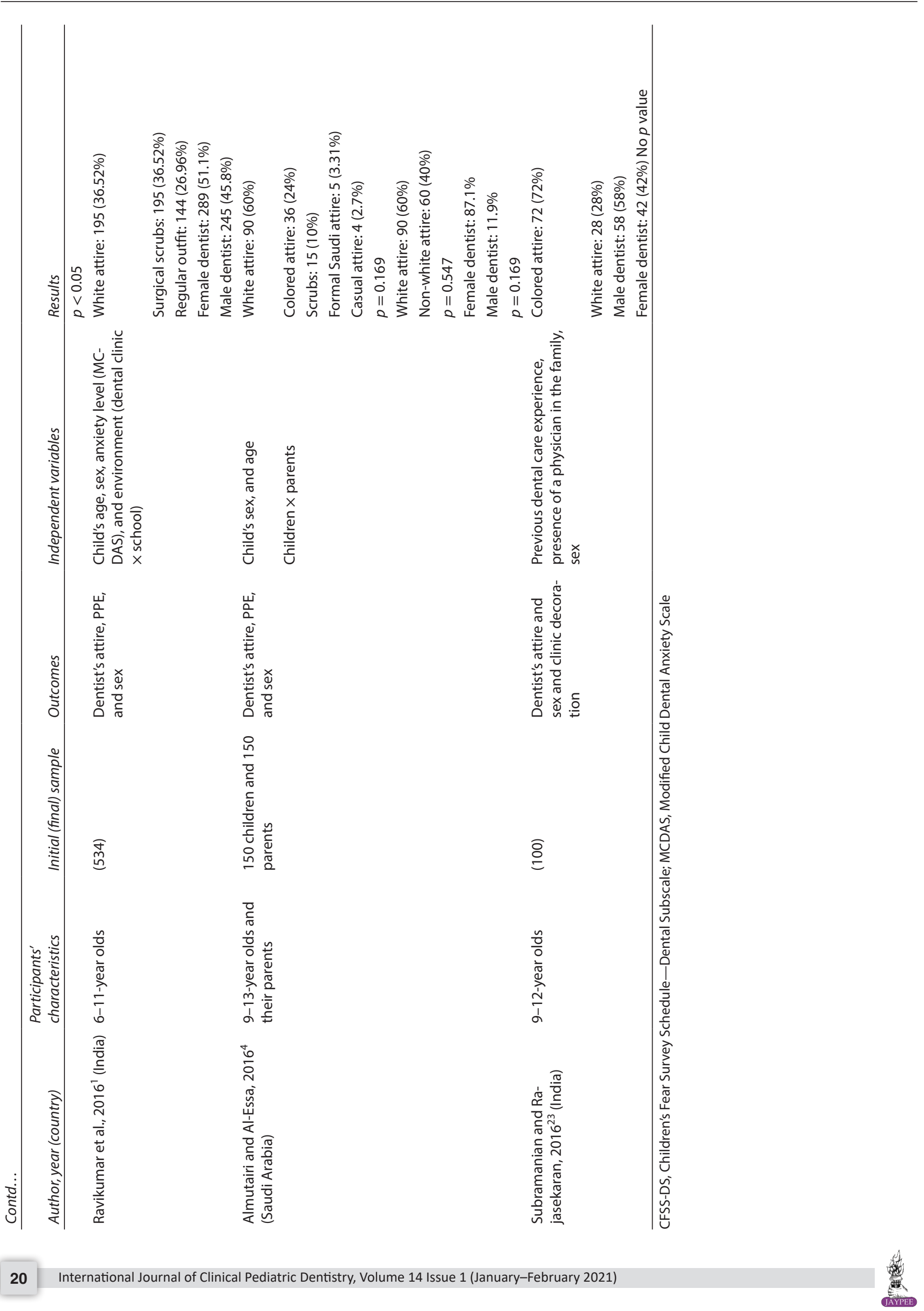


Do Children and Adolescents Prefer Pediatric Attire over White Attire during Dental Appointments?

\begin{tabular}{|c|c|c|c|c|c|c|c|c|}
\hline \multirow[b]{2}{*}{ Study } & \multicolumn{4}{|c|}{ Selection } & \multirow{2}{*}{$\begin{array}{l}\text { Comparability } \\
\text { Based on } \\
\text { design and } \\
\text { analysis }\end{array}$} & \multicolumn{2}{|c|}{ Outcome } & \multirow[b]{2}{*}{ Total (8) } \\
\hline & $\begin{array}{l}\text { Representa- } \\
\text { tiveness of the } \\
\text { sample }\end{array}$ & Sample size & $\begin{array}{l}\text { Non-respond- } \\
\text { ents }\end{array}$ & $\begin{array}{l}\text { Ascertainment } \\
\text { of exposure }\end{array}$ & & $\begin{array}{l}\text { Assessment of } \\
\text { outcome }\end{array}$ & Statistical test & \\
\hline Cohen, $1973^{25}$ & - & - & * & * & * & * & - & (4) \\
\hline Davis et al., $1993^{21}$ & - & - & * & * & $*$ & * & * & (5) \\
\hline $\begin{array}{l}\text { Mistry and Tah- } \\
\text { massebi, } 2009^{18}\end{array}$ & - & - & * & * & * & * & - & (4) \\
\hline Kuscu et al., $2009^{6}$ & * & * & * & * & * & * & - & (6) \\
\hline Al Sarheed, $2011^{10}$ & * & * & * & * & * & * & - & (6) \\
\hline $\begin{array}{l}\text { Münevveroğlu et al., } \\
2014^{22}\end{array}$ & - & - & * & * & * & * & - & (4) \\
\hline Panda et al., $2014^{3}$ & - & - & * & * & $* *$ & $*$ & - & (5) \\
\hline Tong et al., $2014^{19}$ & * & * & * & * & $* *$ & * & * & (8) \\
\hline Ellore et al., $2015^{11}$ & - & - & $*$ & * & $*$ & $*$ & - & (4) \\
\hline $\begin{array}{l}\text { Nirmala et al., } \\
2015^{24}\end{array}$ & - & * & * & * & $* *$ & * & * & (7) \\
\hline Asokan et al., $2016^{20}$ & - & * & * & * & $* *$ & $*$ & $*$ & (7) \\
\hline $\begin{array}{l}\text { Ravikumar et al., } \\
2016^{1}\end{array}$ & - & - & * & * & * & * & - & (4) \\
\hline $\begin{array}{l}\text { Almutairi and Al- } \\
\text { Essa, } 2016^{4}\end{array}$ & - & - & * & * & * & * & * & (5) \\
\hline $\begin{array}{l}\text { Subramanian and } \\
\text { Rajasekaran, } 2016^{23}\end{array}$ & - & - & * & - & * & * & - & (3) \\
\hline
\end{tabular}

Table 4: Results of a meta-analysis of prevalence data reporting effect estimates (ES) and $95 \% \mathrm{Cl}$ of according to preferences of children/adolescents

\begin{tabular}{|c|c|c|c|c|}
\hline Preference for & Number of included studies & $E S(95 \% C l)$ & $z$-test & $p$ value \\
\hline \multicolumn{5}{|l|}{ Primary outcome } \\
\hline Pediatric attire & 10 & $0.33(0.20,0.47)$ & 0.6388 & 0.325 \\
\hline White attire & 13 & $0.41(0.20,0.61)$ & & \\
\hline Pediatric attire among girls* & 4 & $0.15(-0.05,0.35)$ & 0.642 & 0.325 \\
\hline Pediatric attire among boys* & 4 & $0.09(-0.01,0.20)$ & & \\
\hline Pediatric among anxious children/adolescents ${ }^{* *}$ & 2 & $0.03(0.02,0.03)$ & 2.771 & 0.0085 \\
\hline Pediatric among non-anxious children/adolescents ${ }^{* *}$ & 2 & $0.02(0.01,0.02)$ & & \\
\hline White attire among girls* & 5 & $0.25(0.14,0.37)$ & 1.076 & 0.224 \\
\hline White attire among boys* & 5 & $0.18(0.13,0.24)$ & & \\
\hline White attire among anxious children** & 3 & $0.17(0.11,0.22)$ & 0.672 & 0.318 \\
\hline White attire among non-anxious children** & 3 & $0.22(0.09,0.36)$ & & \\
\hline \multicolumn{5}{|l|}{ Secondary outcomes } \\
\hline Female dentist & 8 & $0.62(0.52,0.72)$ & 3.126 & 0.003 \\
\hline Male dentist & 8 & $0.40(0.30,0.49)$ & & \\
\hline Female dentist among girls* & 4 & $0.41(0.25,0.56)$ & 2.198 & 0.036 \\
\hline Female among boys* & 3 & $0.20(0.09,0.30)$ & & \\
\hline Male dentist among girls* & 3 & $0.10(0.01,0.19)$ & 1.879 & 0.068 \\
\hline Male dentist among boys* & 4 & $0.24(0.13,0.36)$ & & \\
\hline Use of PPE & 4 & $0.45(0.17,0.72)$ & 1.248 & 0.182 \\
\hline No use of PPE & 4 & $0.27(0.20,0.33)$ & & \\
\hline
\end{tabular}

* Subgroup analysis by sex

**Subgroup analysis by anxiety groups

media (television dramas and documentaries, newspapers, etc.) or may have been hospitalized. ${ }^{6,24}$

Our results show that pediatric attire seems to be a good option for anxious children and adolescents in the dental office. The results of the study by Asokan et al., ${ }^{20}$ who analyzed the preference of anxious and non-anxious children about the color of the attire, revealed that anxious children prefer colored, pediatric attires. Also, the use of child-friendly attire in the treatment of anxious children 
can help with promoting good communication and management. ${ }^{6}$ On the other hand, Ellore et al. ${ }^{11}$ found a higher preference of children for the use of white attire; they also suggested the use of friendly attires in the management of anxious children. The use of colored attires can help reduce anxiety in dental care resulting in better communication ${ }^{20}$ as children seem to connect colors with positive emotions. ${ }^{28}$

Ravikumar et al. ${ }^{1}$ observed that the age of the child could influence the child's preference. Children under the age of 8 years preferred the dentist to wear casual clothes and those over 8 showed a preference for white attires or surgical scrubs, suggesting that the dentist should consider the age of the patients when dressing to improve the relationship with them.

In general, the female professional had a higher preference when compared to the male professional. These results can be attributed to the fact that younger children perceive their mothers as gentle and welcoming, extrapolating this feeling to the dentist's figure. ${ }^{4}$ There is a perception that female dentists would be more careful, humanized, successful in making the patient feel relaxed, they give more time with explanations, show more empathy, and all that would correlate with patient satisfaction and adherence to treatment. ${ }^{29}$ In the studies of Almutairi and Al-Essa ${ }^{4}$ and Münevveroğlu et al., ${ }^{22}$ the vast majority of children preferred to be treated by female dentists, and the findings of Asokan et al. ${ }^{20}$ pointed out that anxious children tended to prefer female dentists. In addition, girls tended to have a consultation with a female dentist more than boys. According to the child's growth, there is a tendency to prefer the same-sex professional, ${ }^{1,4,10,11,18-20,23}$ which could happen by cultural influence. ${ }^{19,20}$ Moreover, among the four included studies in a meta-analysis, three were for India ${ }^{1,11,20}$ and one from Turkey, ${ }^{22}$ religious and cultural influences might explain the findings, as in these cultures, girls are not supposed to be alone with men.

Surprisingly, the preference for the use of PPE or not did not differ. This can be attributed to the fact that children are aware of the use of PPE in dental care and perceive that its use is necessary, ${ }^{20}$ representing a common practice in modern dentistry. ${ }^{18}$ Al Sarheed ${ }^{10}$ suggested that dentists should explain to their patients the purpose of PPE, thus reducing fear; a suggestion shared by Panda et al. ${ }^{3}$ who in their study verified that the majority of the children did not prefer the use of goggles or cap by the dentist. Two studies found that most of the children and their parents preferred the use of PPE by the dentist (cap, mask, and goggles) probably demonstrating their awareness of the potential transmission of infectious diseases and how such equipment would represent safety. ${ }^{4,11}$ For Davis et al., ${ }^{21}$ PPE alone does not interfere with the child's first impression of the dentist.

As the dentist's attire does not play such a significant role in the child's preference, other aspects such as the dentist's communication skills, behavior, and attitude can have a considerably greater impact on the patient-professional relationship. ${ }^{24}$ Still in this context, Al Sarheed ${ }^{10}$ and Panda et al. ${ }^{3}$ stated that although children may indicate certain preferences regarding the appearance of their dentists, these preferences may mean little when compared to personal attributes of the professional such as kindness, patience, and competence. The preference for colored attire may be much more of the parents ${ }^{11}$ than of the dentists themselves.,11

The risk of bias showed important variability in the studies, mostly regarding the selection of the sample and the statistical analyzes. The main bias of the studies was regarding the representativeness of the sample which was statically calculated in only three studies. . $^{60,19}$ Five studies ${ }^{4,19-21,24}$ presented the statistical analysis of all comparisons. Also, not all studies adjusted for all confounding variables. The lack of adjustment of the confounders may explain the high heterogeneity found in the meta-analysis. Some statistical heterogeneity in observational data is expected due to confounding, this may be due to age differences, how the preference data was collected, cultural and religious status. In the present systematic review, 11 studies had Asian origin, 6 from India, 2 from Turkey, 2 from Saudi Arabia, and 1 from Singapore. This may be an indication that these countries are giving greater importance to the professional attire used in the dental care of children. However, it can also be interpreted as a limitation of this systematic review, since preferences and behaviors are related to cultural aspects, both in relation to the preference for the attire used by the professionals and in relation to the preference for the sex of the dentists. Preference for a female dentist by girls can have limited external validity. Thus, the smaller amount of research conducted in other regions of the world, two North American and one European might influence the outcome of the meta-analyzes. Also, the results may be extrapolated with caution to countries from those regions. Research should be done with children from other regions to assess whether culture influences this aspect of pediatric dental care.

On the other hand, it is worth noting that the similarity of the methodologies used in the fourteen included studies enabled the inclusion of all the studies in the meta-analyzes. To confirm the scientific evidence, we suggest more prospective studies to follow-up if preferences keep being the same as children grown up.

\section{References}

1. Ravikumar D, Gurunathan D, Karthikeyan S, et al. Age and environment determined children's preference towards dentist attire - a cross-sectional study. J Clin Diagnostic Res 2016;10(10):16-19.

2. Young JW. Symptom disclosure to male and female physicians: effects of sex, physical attractiveness, and symptom type. J Behav Med 1979;2(2):159-169. DOI: 10.1007/BF00846664.

3. Panda A, Garg I, Bhobe AP. Children's perspective on the dentist's attire. Int J Paediatr Dent 2014;24(2):98-103. DOI: 10.1111/ipd.12032.

4. Almutairi MA, Al-Essa NA. Children and parent's preferences of dentists' attire. Pakistan Oral Dent J 2016;36(3):2-5.

5. McKinstry B, Wang JX. Putting on the style: what patients think of the way their doctor dresses. Br J Gen Pract 1991;41(348):275-278.

6. Kuscu OO, Çaglar E, Kayabasoglu N, et al. Short communication: preferences of dentist's attire in a group of Istanbul school children related with dental anxiety. Eur Arch Paediatr Dent 2009;10(1):38-41. DOI: 10.1007/BF03262666.

7. Brandt LJ. On the value of an old dress code in the new millennium. Arch Intern Med 2003;163(11):1277-1281. DOI: 10.1001/archinte.163.11.1277.

8. Lill MM, Wilkinson TJ. Judging a book by its cover: descriptive survey of patients' preferences for doctors' appearance and mode of address. BMJ 2005;331(7531):24-31. DOI: 10.1136/bmj.331.7531.1524.

9. Vagnoli L, Caprilli S, Robiglio A, et al. Clown doctors as a treatment for preoperative anxiety in children: a randomized, prospective study. Pediatr 2005;116(4):563-567. DOI: 10.1542/peds.2005-0466.

10. Al Sarheed M. Children's perception of their dentists. Res J Pharm Biol Chem Sci 2011;7(2):787-791.

11. Kumar V, Kamavaram Ellore VP, Mohammed M, et al. Children and parent's attitude and preferences of dentist's attire in pediatric dental practice. Int J Clin Pediatr Dent 2015 ;8(2):102-107. DOI: 10.5005/ jp-journals-10005-1293. 
12. Moher D, Liberati A, Tetzlaff J, et al. Preferred reporting items for systematic reviews and meta-analyses: the PRISMA statement. PLoS Med 2009;6(7):e1000097. DOI: 10.1371/journal.pmed.1000097.

13. Herzog R, Álvarez-Pasquin J, Díaz C, et al. Are healthcare workers' intentions to vaccinate related to their knowledge, beliefs and attitudes? a systematic review. BMC Public Health 2013;13(1):154. DOI: 10.1186/1471-2458-13-154.

14. Modesti PA, Reboldi G, Cappuccio FP, et al. Group on CV risk in low resource settings. panethnic differences in blood pressure in Europe: a systematic review and meta-analysis. PLoS ONE 2016;11(1):e0147601. DOI: 10.1371 /journal.pone.0147601.

15. Deeks JJ, Higgins JPT, Altman DG. Analysing data and undertaking meta-analyses. In: Higgins JPT, Green S, ed. Cochrane Handbook for Systematic Reviews of Interventions, ch. 9, Chichester: WileyBlackwell; 2015. pp. 243-296.

16. Altman DG, Bland JM. Statistics notes: interaction revisited: the difference between two estimates. BMJ 2003;326(7382):219. DOI: 10.1136/bmj.326.7382.219.

17. Egger M, Smith GD, Schneider M, et al. Bias in metaanalysis detected by a simple, graphical test. BMJ 1997;315(7109):629-634. DOI: 10.1136/ bmj.315.7109.629.

18. Mistry D, Tahmassebi JF. Children's and parents' attitudes towards dentists' attire. Eur Arch Paediatr Dent 2009;10(4):237-240. DOI: 10.1007/BF03262689.

19. Tong HJ, Khong J, Ong C, et al. Children's and parents' attitudes towards dentists' appearance, child dental experience and their relationship with dental anxiety. Eur Arch Paediatr Dent 2014;15(6):377-384. DOI: 10.1007/s40368-014-0126-z.
20. Asokan $A$, Kambalimath $H$, Patil $R$, et al. A survey of the dentist attire and gender preferences in dentally anxious children. J Indian Soc Pedod Prev Dent 2016;34(1):30-35. DOI: 10.4103/0970-4388.175507.

21. Davis R, Mckibben DMDDH, Nazif MM, et al. Child reaction to protective garb at the first dental visit. Pediatr Dent 1993;16(2):86-87.

22. Münevveroğlu AP, Akgöl BB, Erol T. Assessment of the feelings and attitudes of children towards their dentist and their association with oral health. ISRN Dent 2014;2014:1-4. DOI: 10.1155/2014/867234.

23. Subramanian $P$, Rajasekaran $S$. Children's perception of their dentists. Res J Pharm Biol Chem Sci 2016;7(2):787-791.

24. Nirmala SVSG, Veluru S, Nuvvula S, et al. Preferences of dentist's attire by anxious and nonanxious Indian children. J Dent Child 2015;82(2):97-101.

25. Cohen SD. Children's attitudes toward dentists' attire. ASDC J Dent Child 1973;40(4):285-287.

26. Nair BR, Mears SR, Hitchcock KI, et al. Evidence-based physicians' dressing: a crossover trial. Med J Aust 2002;177(11):681-682. DOI: 10.5694/j.1326-5377.2002.tb05017.x.

27. McCarthy JJ, McCarthy MC, Eilert RE. Children's and parents' visual perception of physicians. Clin Pediatr (Phila) 1999;38(3):145-152. DOI: 10.1177/000992289903800304.

28. Debbie JP, Hannah B, Pamela Q. Emotional understanding and color-emotion associations in children aged 7-8 years. Child Dev Res 2012;201:1-9.

29. Corah NL, O'Shea RM, Bissell GD, et al. The dentist-patient relationship: perceived dentist behaviors that reduce patient anxiety and increase satisfaction. J Am Dent Assoc 1988;116(1):73-76. DOI: 10.14219/jada. archive.1988.0162. 


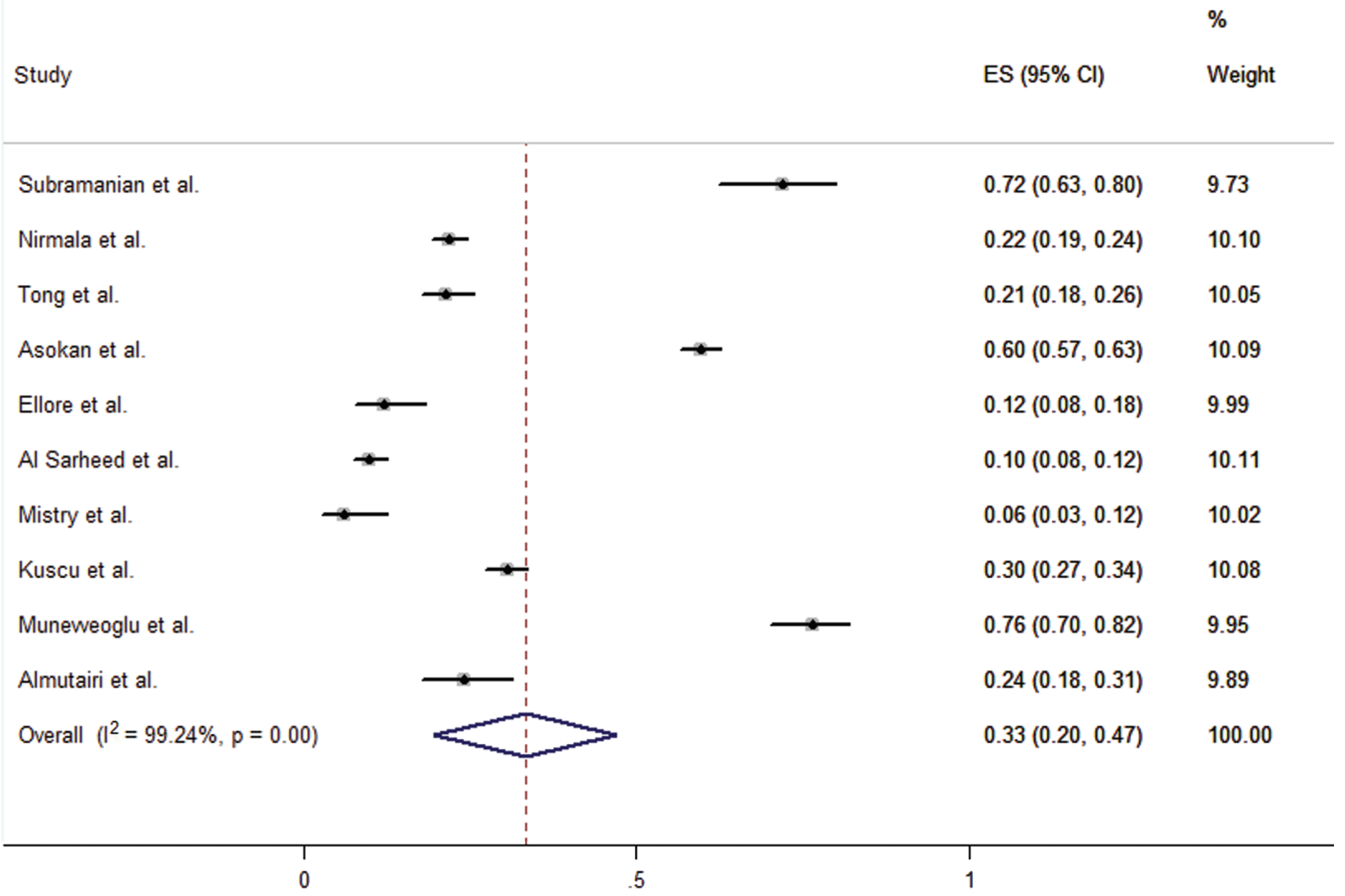

Supplementary Fig. 1: The proportion of the preference for pediatric attire and $95 \% \mathrm{Cl}$

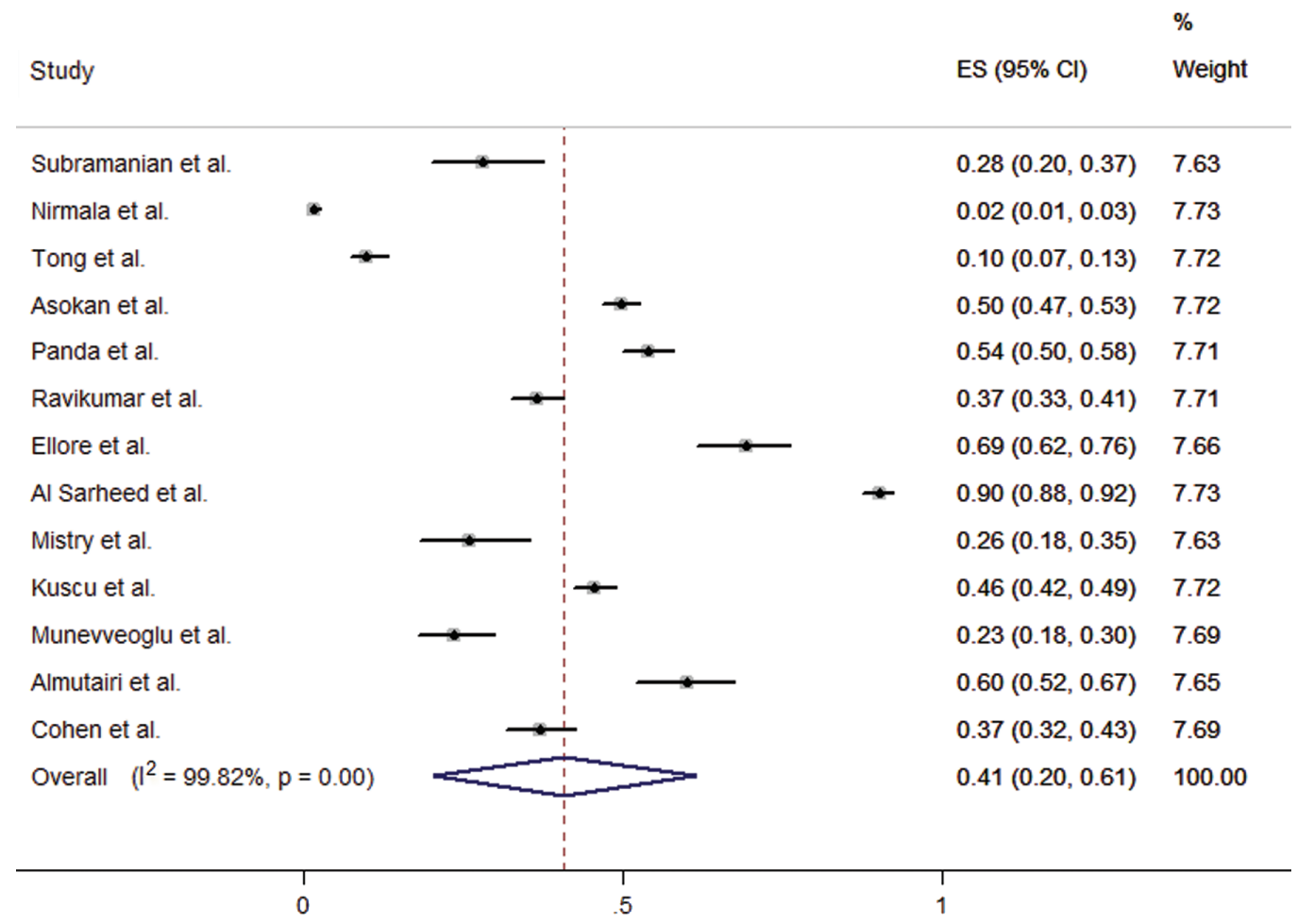

Supplementary Fig. 2: The proportion of the preference for white attire and $95 \% \mathrm{Cl}$ 


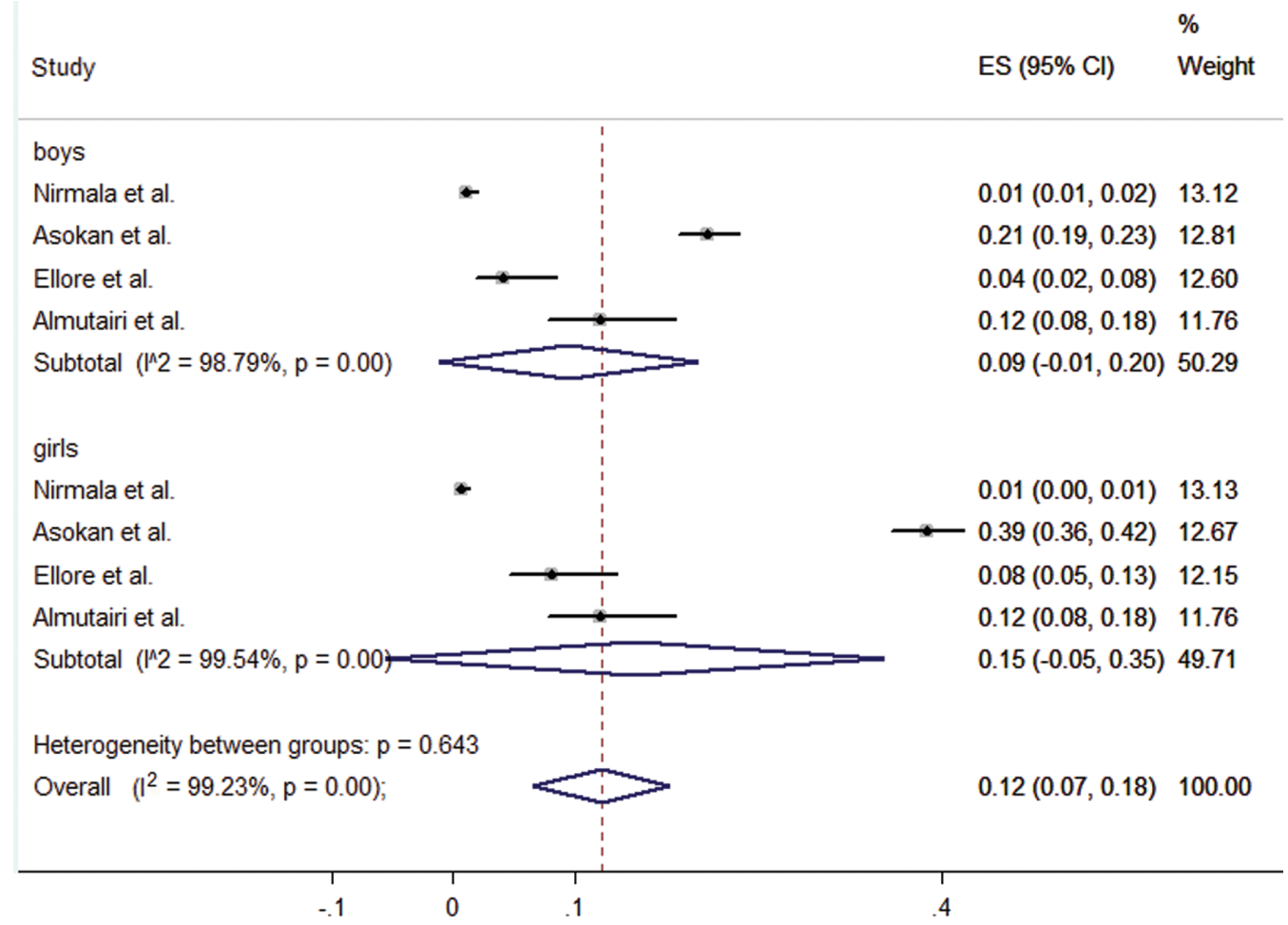

Supplementary Fig. 3: Subgroup analysis of the proportion of the preference of pediatric attire according to the sex of the child/adolescent

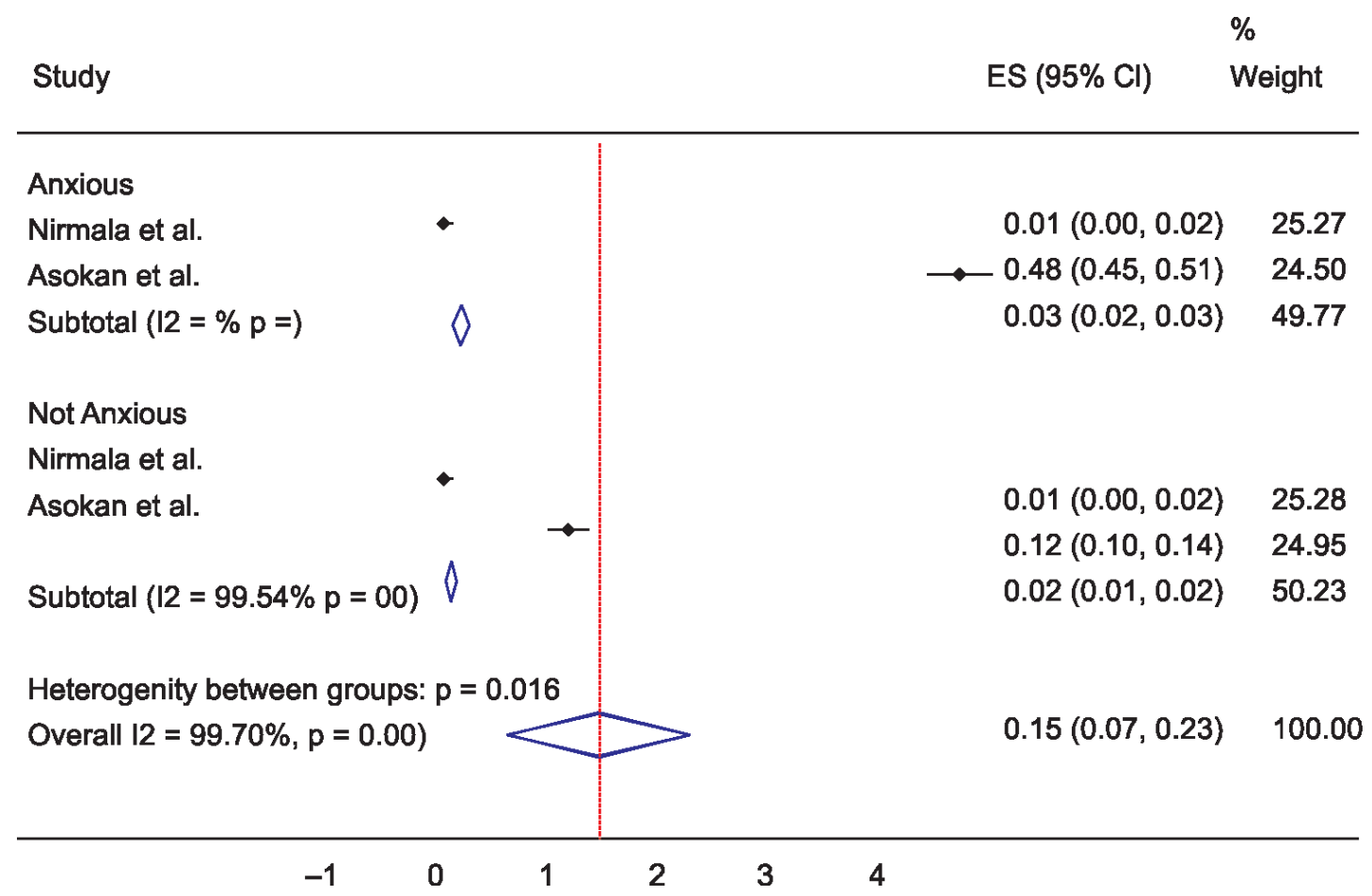

Supplementary Fig. 4: Subgroup analysis of the proportion of the preference of pediatric attire according to anxiety or not 


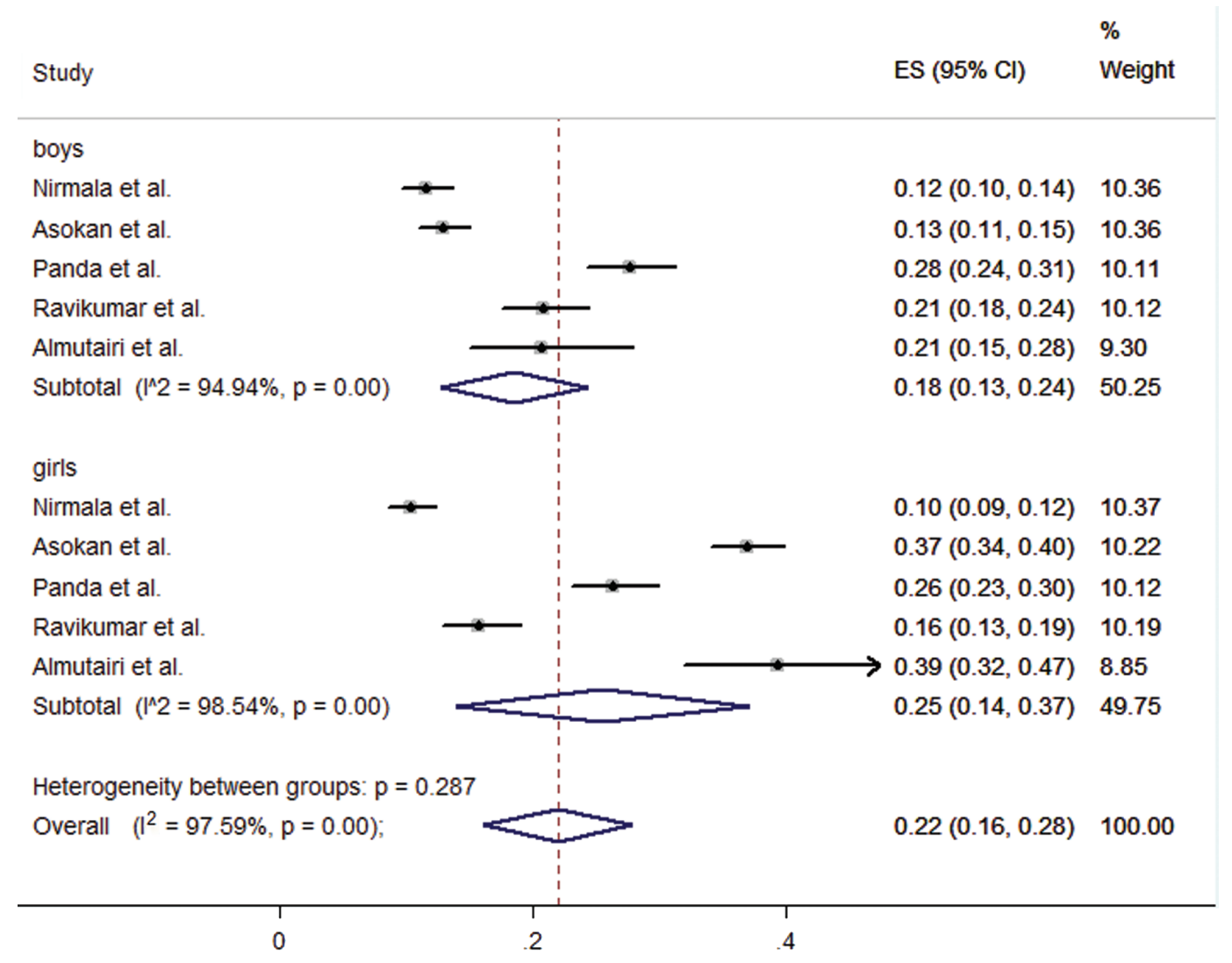

Supplementary Fig. 5: Subgroup analysis of the proportion of the preference of white attire according to the sex of the child/adolescent

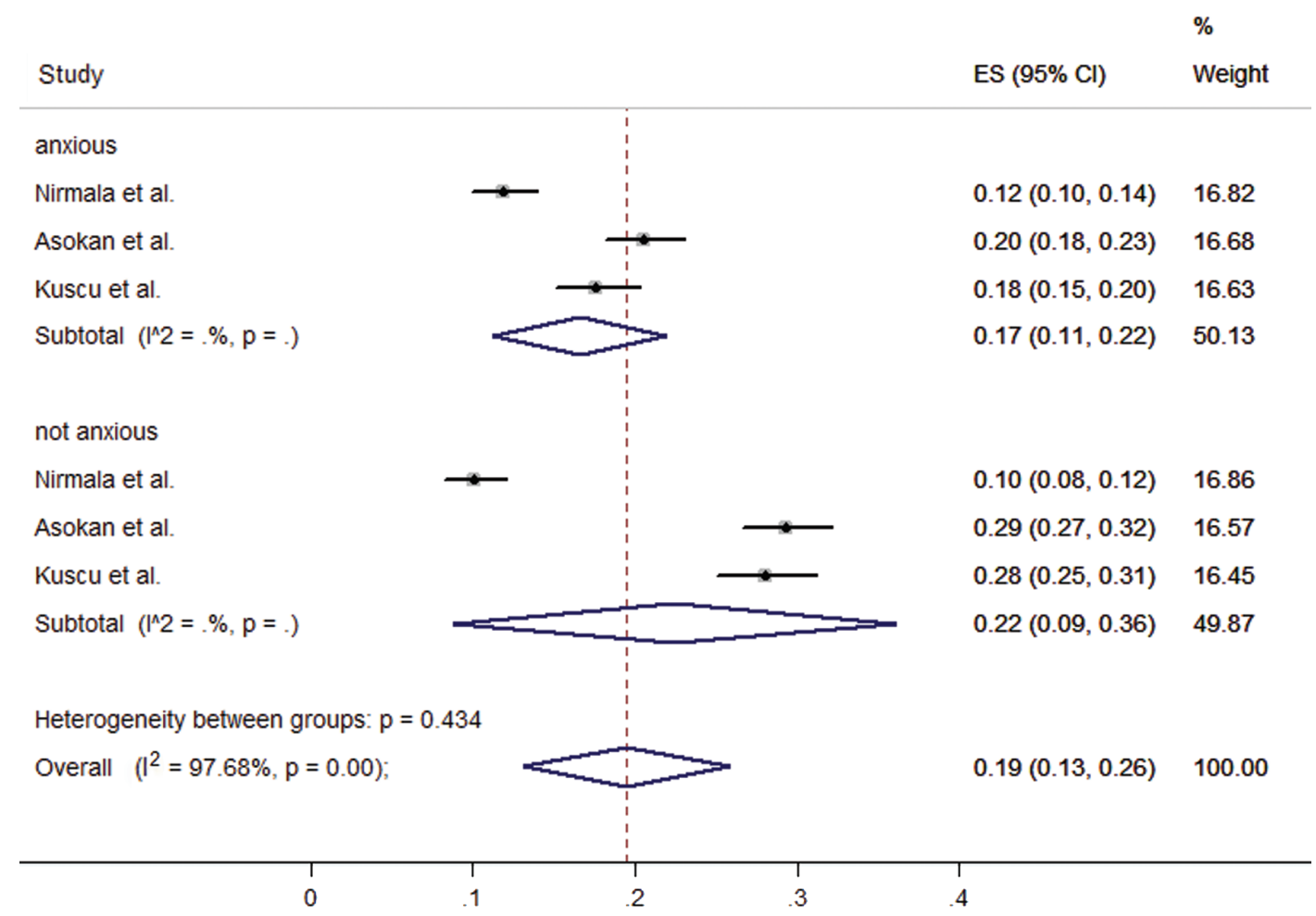

Supplementary Fig. 6: Subgroup analysis of the proportion of the preference of white attire according to anxiety or not 


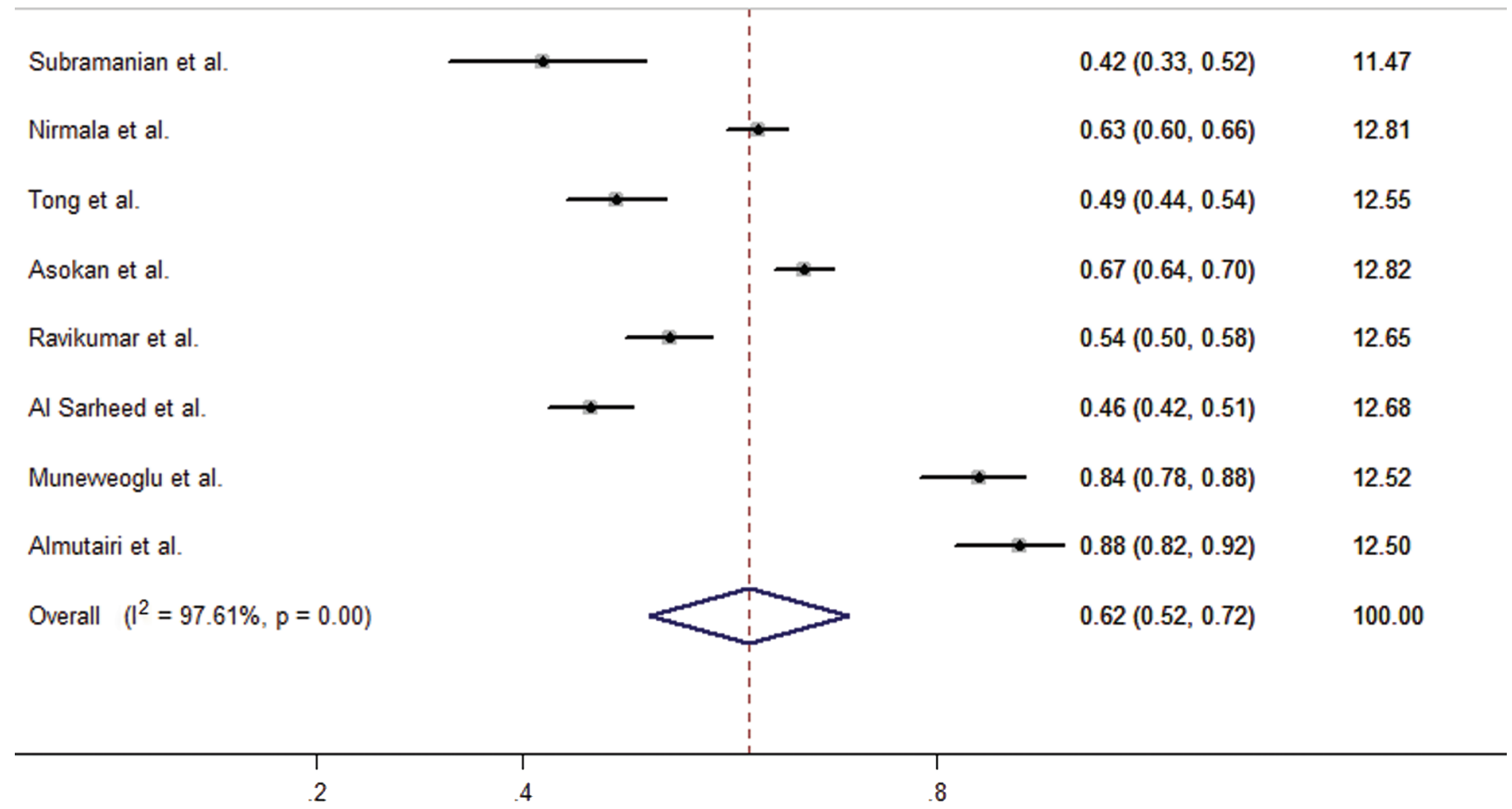

Supplementary Fig. 7: The overall proportion of the preference for a female dentist

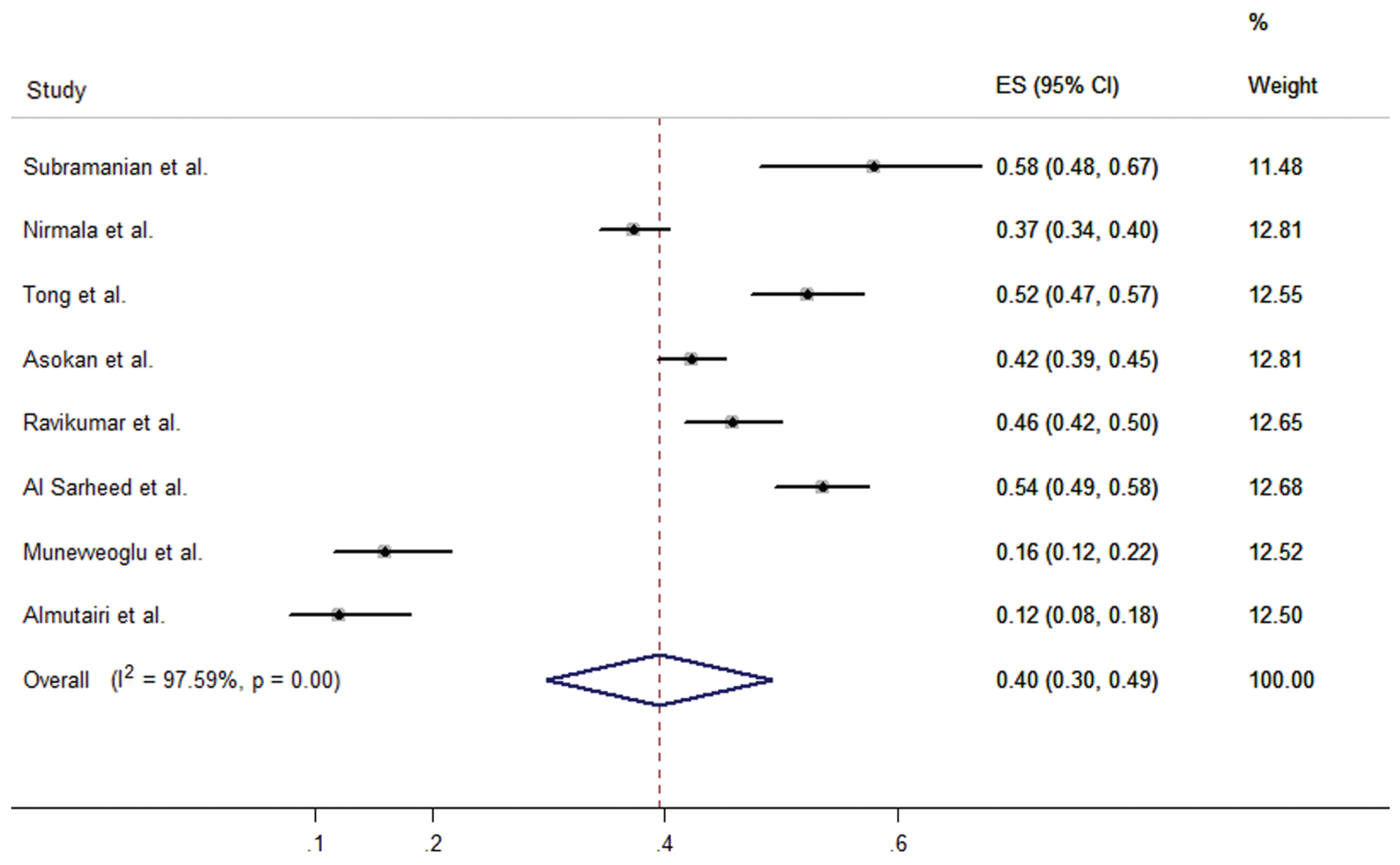

Supplementary Fig. 8: The overall proportion of the preference for a male dentist 


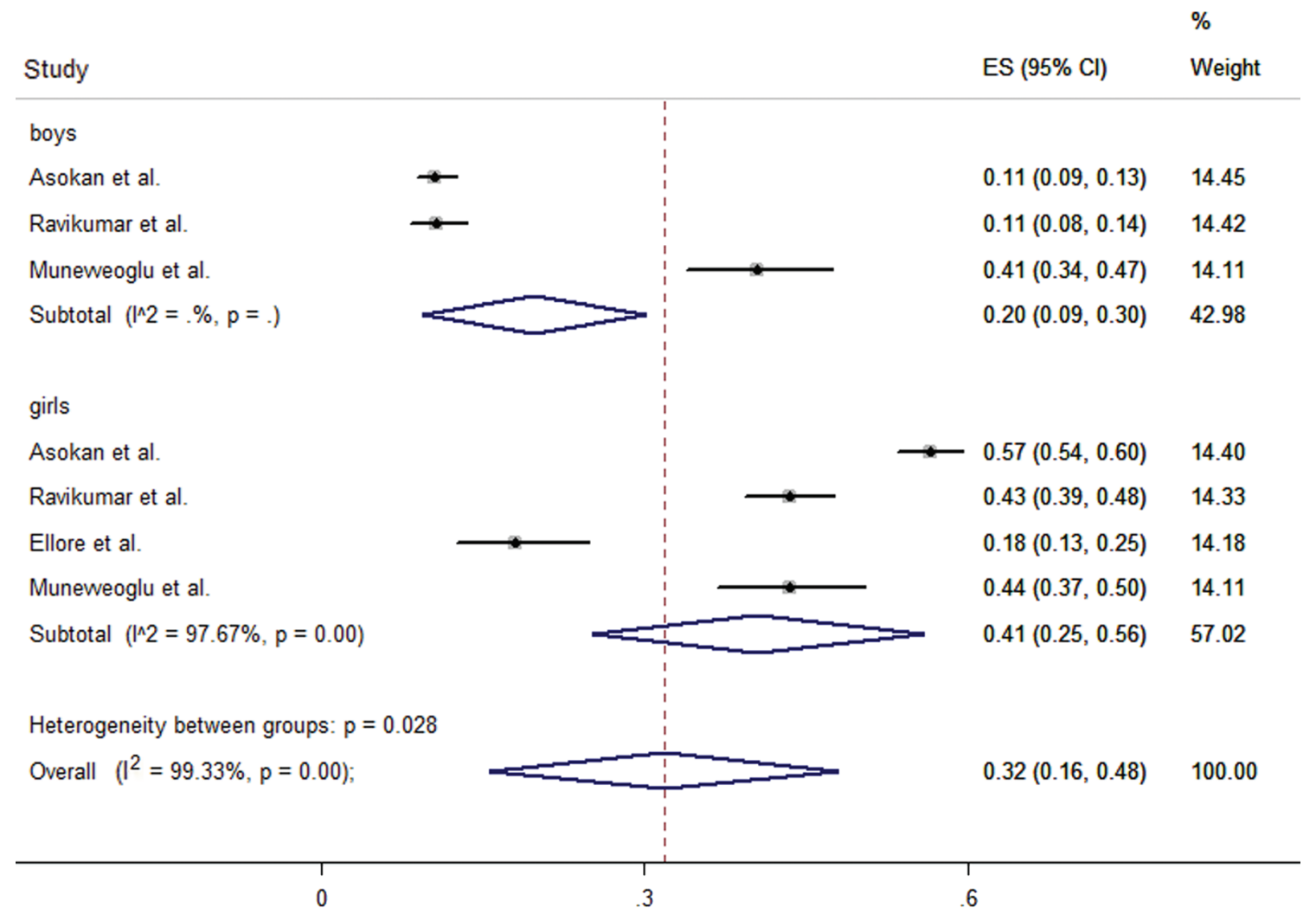

Supplementary Fig. 9: Subgroup analysis of the preference for a female dentist according to the sex of the child/adolescent

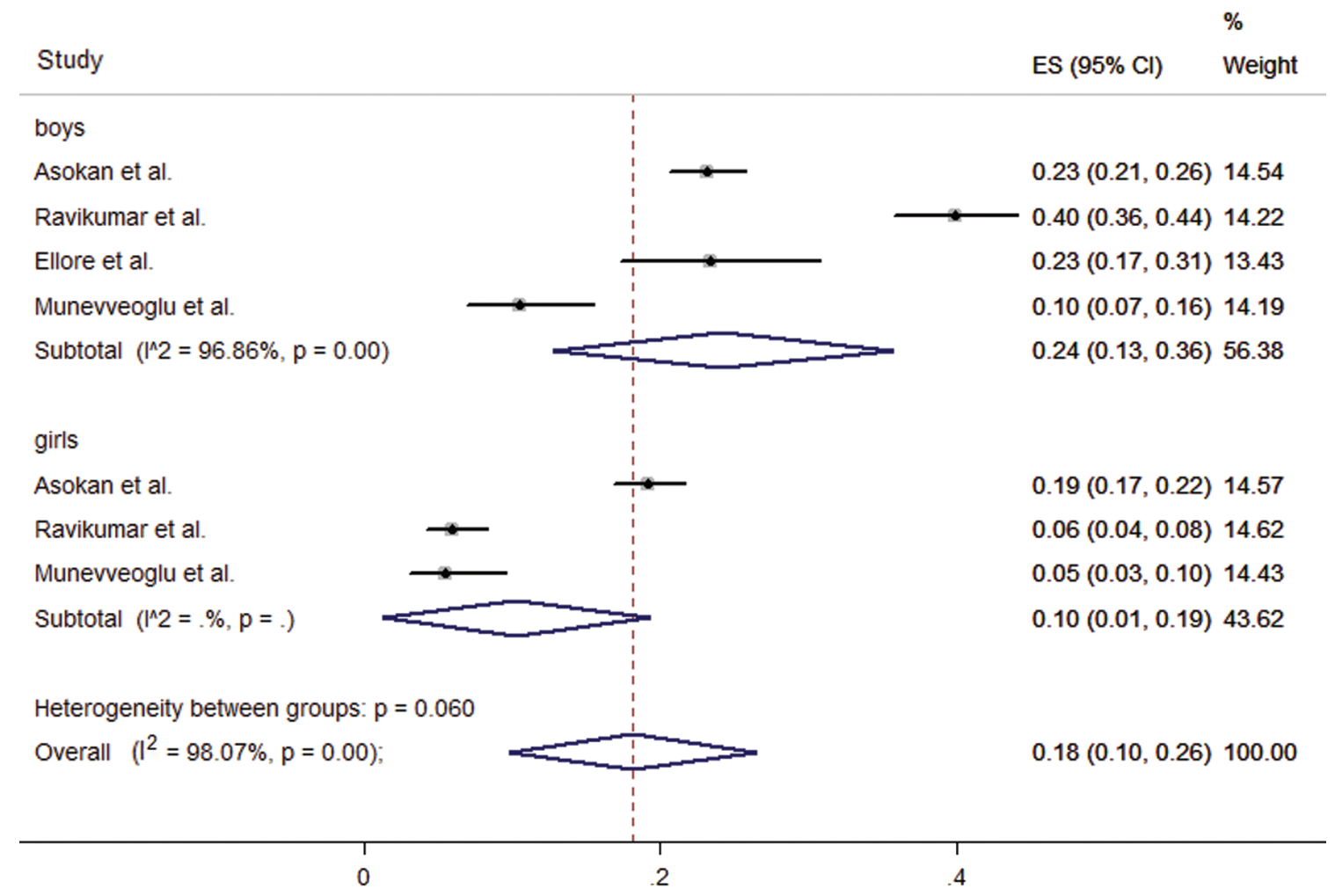

Supplementary Fig. 10: Subgroup analysis of the preference for a male dentist according to the sex of the child/adolescent 


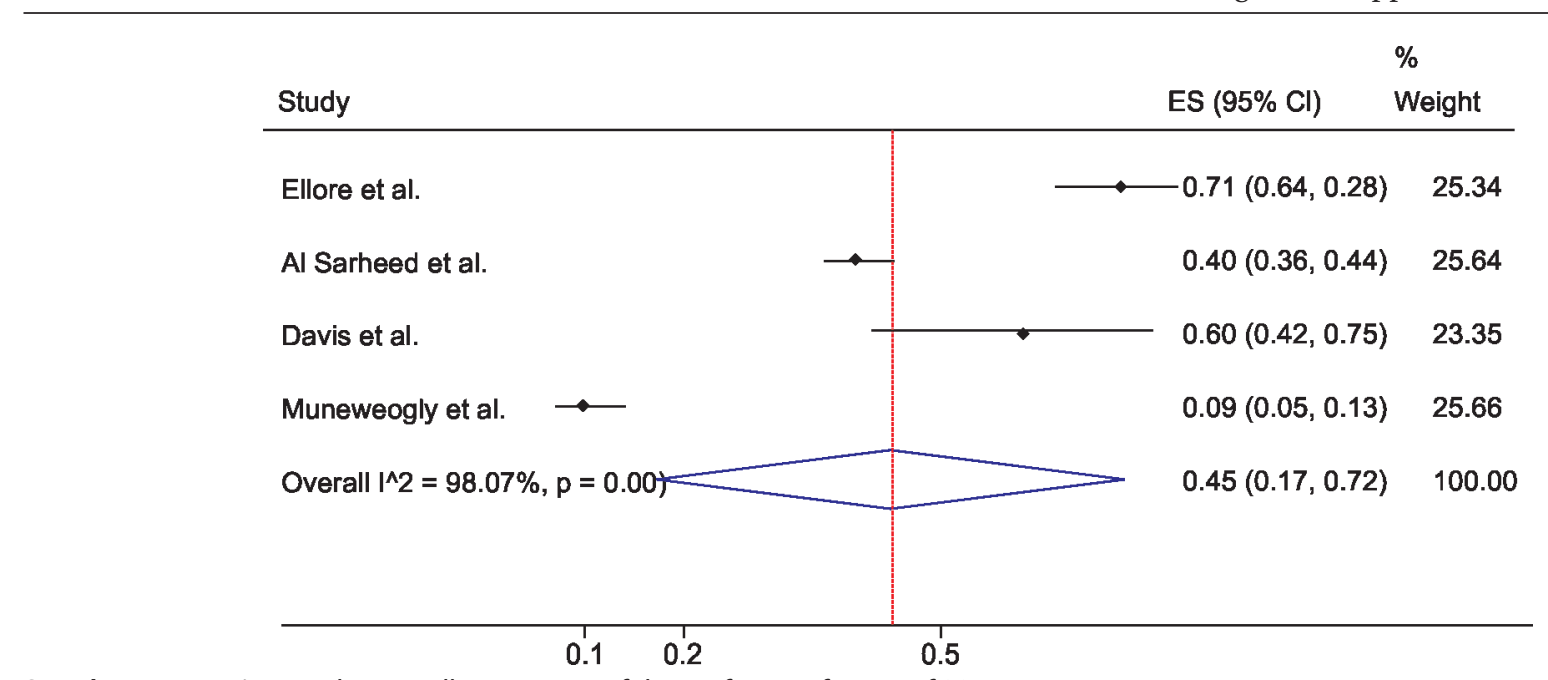

Supplementary Fig. 11: The overall proportion of the preference for use of PPE

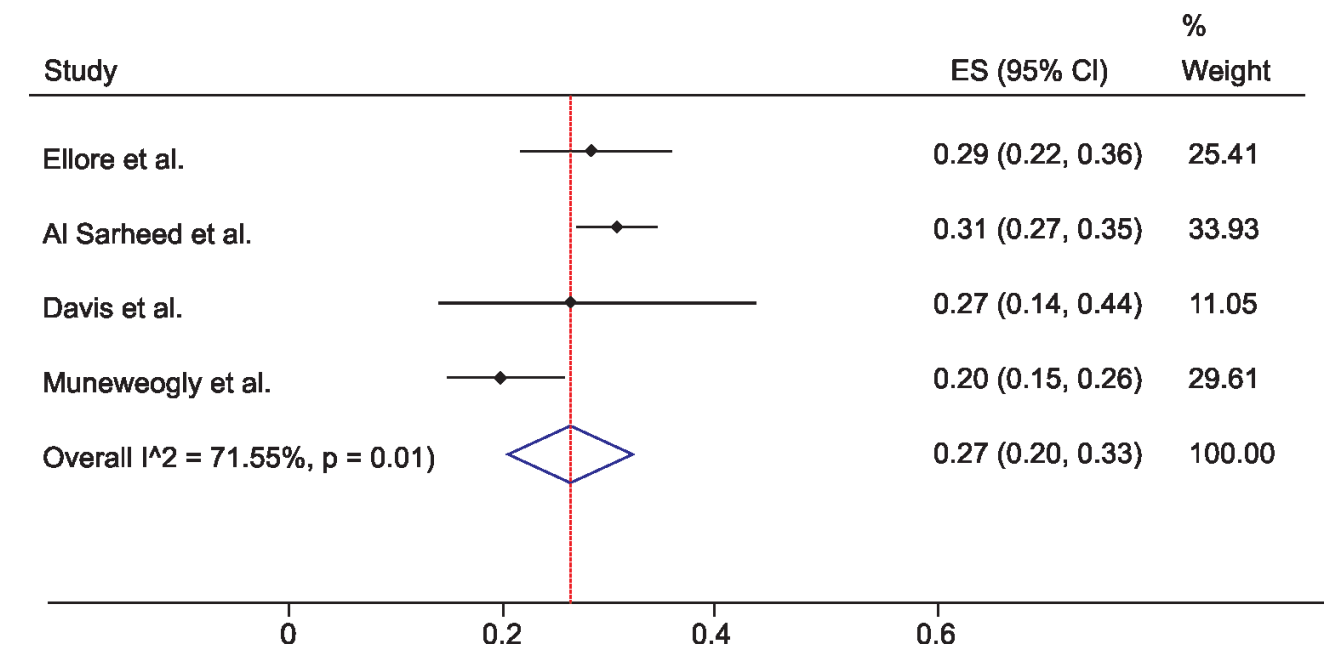

Supplementary Fig. 12: The overall proportion of the preference for not using PPE 